\title{
Microwave-Assisted Combustion Synthesis of Nano Iron Oxide/Iron-Coated Activated Carbon, Anthracite, Cellulose Fiber, and Silica, with Arsenic Adsorption Studies
}

\author{
Mallikarjuna N. Nadagouda and Darren A. Lytle \\ Water Supply and Water Resources Division, National Risk Management Research Laboratory, United States Environmental Protection \\ Agency, 26 West Martin Luther King Drive, Cincinnati, OH 45268, USA \\ Correspondence should be addressed to Mallikarjuna N. Nadagouda, nadagouda.mallikarjuna@epa.gov
}

Received 9 March 2011; Accepted 18 April 2011

Academic Editor: Thomas F. Speth

Copyright (C 2011 M. N. Nadagouda and D. A. Lytle. This is an open access article distributed under the Creative Commons Attribution License, which permits unrestricted use, distribution, and reproduction in any medium, provided the original work is properly cited.

Combustion synthesis of iron oxide/iron coated carbons such as activated carbon, anthracite, cellulose fiber, and silica is described. The reactions were carried out in alumina crucibles using a Panasonic kitchen microwave with inverter technology, and the reaction process was completed within a few minutes. The method used no additional fuel and nitrate, which is present in the precursor itself, to drive the reaction. The obtained samples were then characterized with X-ray mapping, scanning electron microscopy (SEM), energy dispersive X-ray analysis (EDS), selected area diffraction pattern (SAED), transmission electron microscopy (TEM), $\mathrm{X}$-ray diffraction (XRD), and inductively coupled plasma (ICP) spectroscopy. The size of the iron oxide/iron nanoparticle-coated activated carbon, anthracite, cellulose fiber, and silica samples were found to be in the nano range (50-400 nm). The iron oxide/iron nanoparticles mostly crystallized into cubic symmetry which was confirmed by SAED. The XRD pattern indicated that iron oxide/iron nano particles existed in four major phases. That is, $\gamma$ - $\mathrm{Fe}_{2} \mathrm{O}_{3}, \alpha-\mathrm{Fe}_{2} \mathrm{O}_{3}, \mathrm{Fe}_{3} \mathrm{O}_{4}$, and Fe. These iron-coated activated carbon, anthracite, cellulose fiber, and silica samples were tested for arsenic adsorption through batch experiments, revealing that few samples had significant arsenic adsorption.

\section{Introduction}

Arsenic (As) contamination is one of the most challenging environmental problems today. Millions of people worldwide are exposed to naturally occurring As-contaminated groundwater, which they use as their sole source of drinking water. Increased use of groundwater as a source for drinking water has caused serious health problems such as neurological, dermatological, gastrointestinal, and cardiorenal diseases; arsenic is also a suspected carcinogen. Furthermore, recent research has suggested that As acts as an endocrine disruptor at extremely low concentrations. Recently, because of its high nuisance value, The U.S. Environmental Protection Agency has revised the maximum contaminant level (MCL) of arsenic in drinking water from 50 to $10 \mu \mathrm{g} / \mathrm{L}$. As a result, there is a need to develop simple, low-cost methods for the removal of As from groundwater used as a source for drinking water.
Numerous materials have been used for arsenic adsorption such as rice husk (1), calcined and uncalcined layered double hydroxides (2), low-cost sorbents (3), aluminium oxide and phyllosilicate mineral surfaces in smelter-impacted soils (4), natural soil (5), waste biomass with a high fibrous protein content obtained from chicken feathers (6), nanocrystalline anatase form of titanium dioxide prepared by hydrolysis of titanium sulfate solution (7), and activated carbons prepared from solvent extracted olive pulp and olive stones (8).

There is now a growing interest, however, in using iron and its oxide form for their superior adsorption capability, when compared with the above mentioned alternatives [114]. Zhang et al. [1] reported that a novel Fe-Mn binary oxide adsorbent was developed for effective As (III) removal, which is more difficult to remove from drinking water and much more toxic to humans than As (V). The synthetic adsorbent 


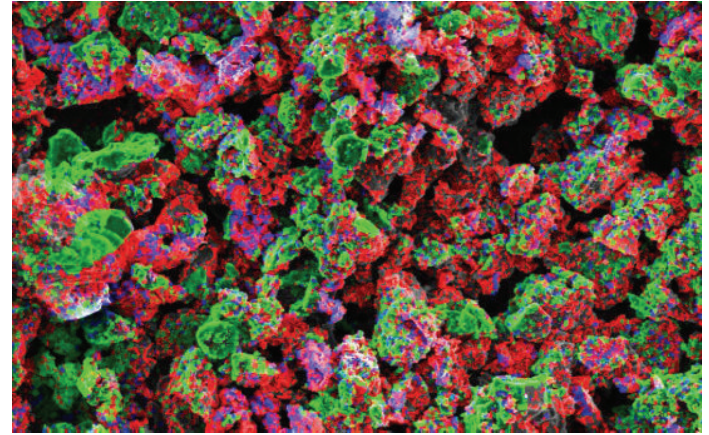

(a)

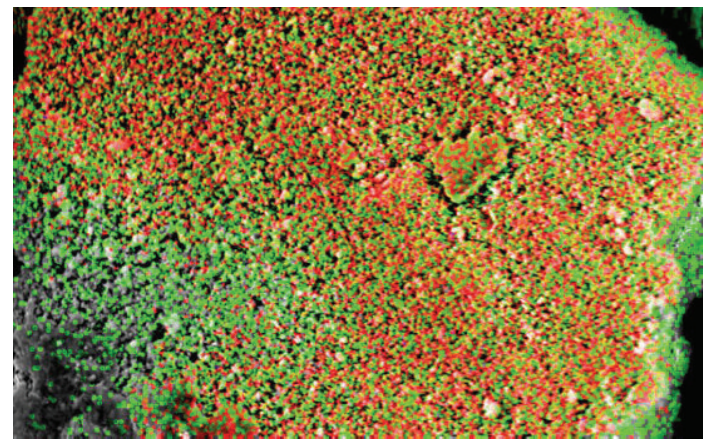

(c)

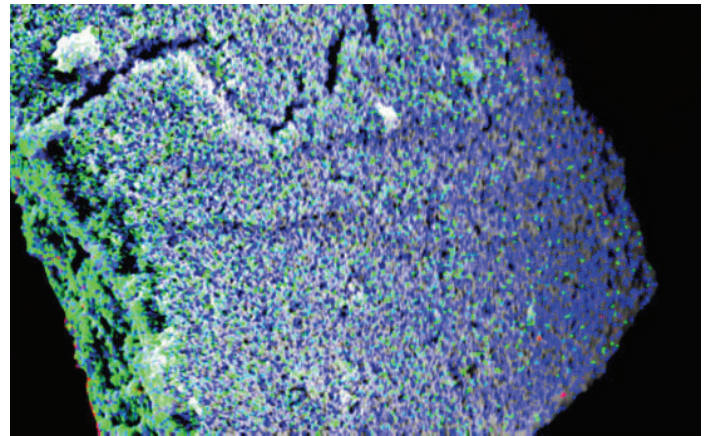

(b)

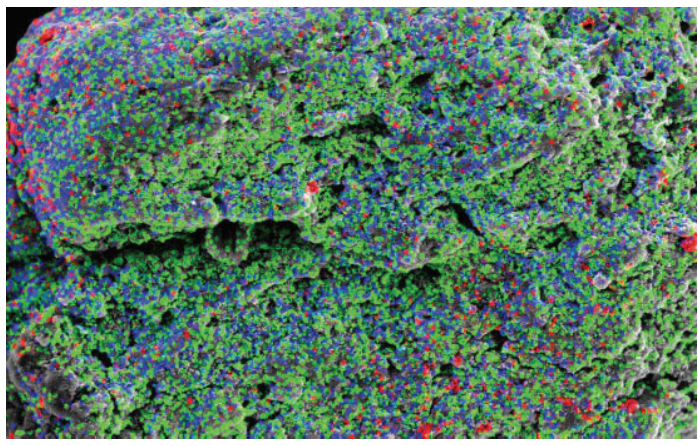

(d)

Figure 1: X-ray mapping images of (a) MN-1 (red-Fe, green-C, and blue-O), (b) MN-2 (blue-Fe, green-O, and red-C), (c) MN-3 (green-Fe, red-O, and blue-C), and (d) MN-4 (red-Silica, green-Fe, and blue-O).

showed a significantly higher As (III) uptake than As (V). Zhang et al. [2] showed that the bimetal oxide adsorbent showed a significantly higher As (V) adsorption capacity than the referenced $\mathrm{Ce}$ and $\mathrm{Fe}$ oxides $\left(\mathrm{CeO}_{2}\right.$ and $\left.\mathrm{Fe}_{3} \mathrm{O}_{4}\right)$ prepared by the same procedure, and some other arsenate adsorbents reported recently. Adsorption kinetics of arsenate and dimethylarsinate (DMA) on goethite (alpha-FeOOH) were investigated at different $\mathrm{pH}$ values and inert electrolyte concentrations. Their adsorption kinetics were described and compared using Elovich plots [4].

Nanoscale zero-valent iron was tested for the removal of As (III) in anoxic groundwater. Arsenic (III) adsorption kinetics were rapid and occurred on a scale of minutes following a pseudo-first-order rate expression with observed reaction rate constants of $0.07-1.3 \mathrm{~min}^{-1}$, and these values were about 1000 times higher than literature values for As (III) adsorption on micron-sized Iron [6]. New adsorbent, bead cellulose loaded with iron oxyhydroxide was applied for the adsorption and removal of arsenate and arsenite from aqueous systems. The adsorption capacity for arsenite and arsenate was 99.6 and $33.2 \mathrm{mg} / \mathrm{g}$ bead cellulose loaded with iron oxyhydroxide at $\mathrm{pH} 7.0$, with an $\mathrm{Fe}$ content of $220 \mathrm{mg} / \mathrm{mL}$. Kinetic data suggests a pseudo-second-order reaction model. Arsenate elimination was favored at acidic $\mathrm{pH}$, whereas the adsorption of arsenite by bead cellulose loaded with iron oxyhydroxide was found to be effective in a wide $\mathrm{pH}$ range of 5-11 [12]. Effort from our laboratory to develop simple, low-cost methods for the removal of As from groundwater used as a source for drinking water herein, we report on studies of iron oxide/iron nanoparticle-coated activated carbon, anthracite, cellulose fiber, and silica sample preparation using microwave-assisted combustion synthesis and their application in arsenic removal. The reaction occurs within a few minutes, uses no additional fuel, and is easy to process.

\section{Experimental}

The experimental procedure was carried out using $\mathrm{Fe}$ $\left(\mathrm{NO}_{3}\right)_{3} \cdot 9 \mathrm{H}_{2} \mathrm{O}$ (Aldrich, 99\%) with various different carbons, and the composition ratio is shown in Table 1. The different ratio of $\mathrm{Fe}\left(\mathrm{NO}_{3}\right)_{3} \cdot 9 \mathrm{H}_{2} \mathrm{O}$ to activated carbon, anthracite, cellulose fiber, and silica was mixed using a pestle and mortar, and then transferred to an alumina crucible. The mixtures were then heated under microwave irradiation (Panasonic kitchen microwave oven with inverter technology) for one to three minutes (Table 1).

Batch experiments were conducted for arsenic adsorption at room temperature. A stock arsenic solution was prepared by dissolution of $0.12 \mathrm{~g} \mathrm{Na}_{2} \mathrm{HAsO}_{4}$ into $4.0 \mathrm{~L} \mathrm{H}_{2} \mathrm{O}$ resulting in an initial concentration of $10 \mathrm{mg} / \mathrm{L}$. Additionally, dissolved inorganic carbon was added by dissolving $1.40 \mathrm{~g}$ $\mathrm{NaHCO}_{3}$ into the stock solution resulting in a dissolved in inorganic carbon level. Subsequently, the $\mathrm{pH}$ was adjusted to 7.0 by computer-controlled automatic titration. To highdensity polyethylene bottles, $300 \mathrm{~mL}$ of stock solution and $0.25 \mathrm{~g}$ of synthesized adsorption media (MN-1 to MN-7) 


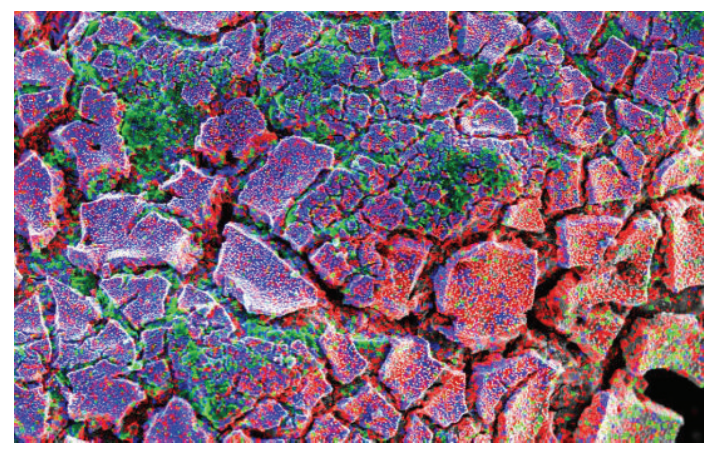

(a)

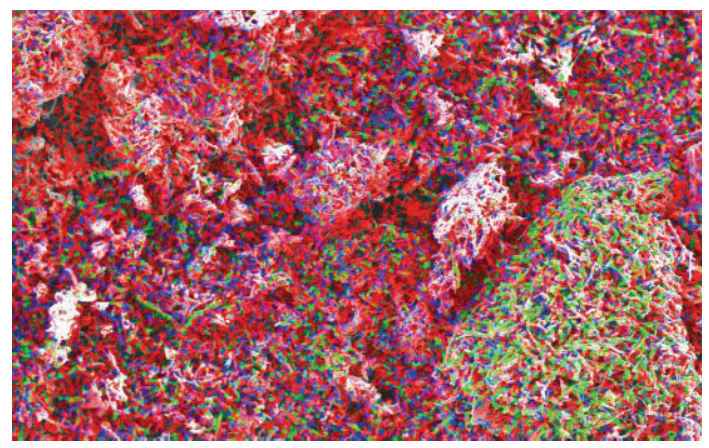

(c)

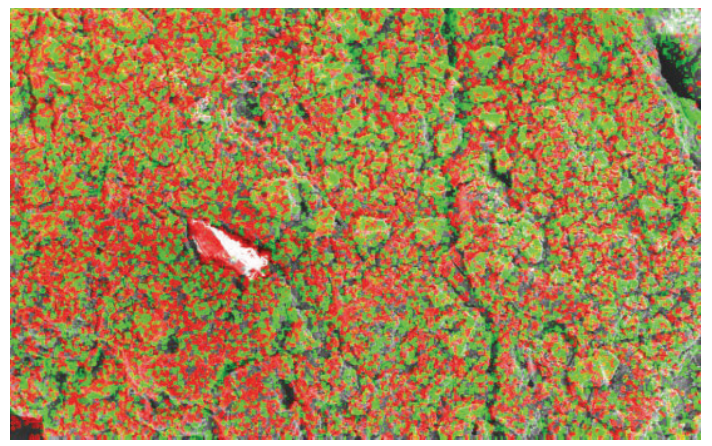

(b)

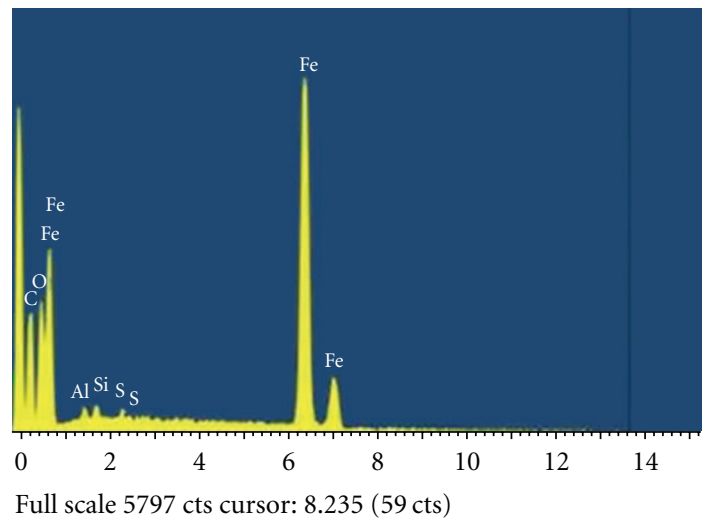

(d)

Figure 2: X-ray mapping images of (a) MN-5 (red-Fe, green-C, and blue-O), (b) MN-6 (blue-Fe, green-O, and red-C), (c) MN-7 (green-Fe, red-O, and blue-C), and (d) EDS spectrum of $\mathrm{MN}-7$.

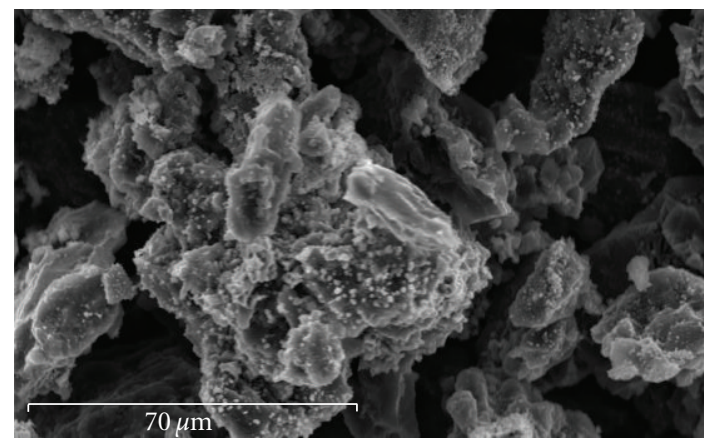

(a)

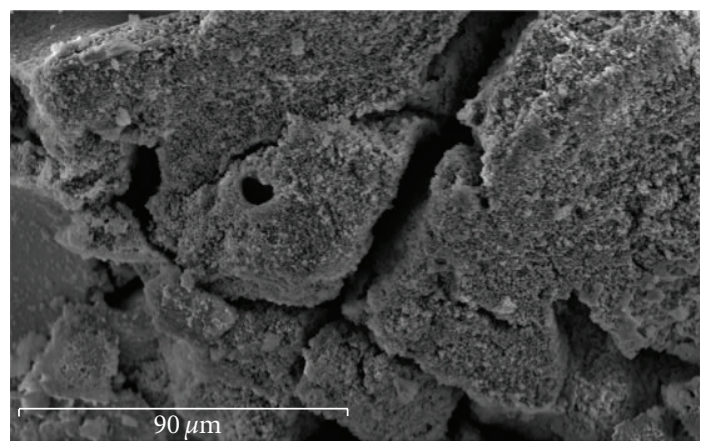

(c)

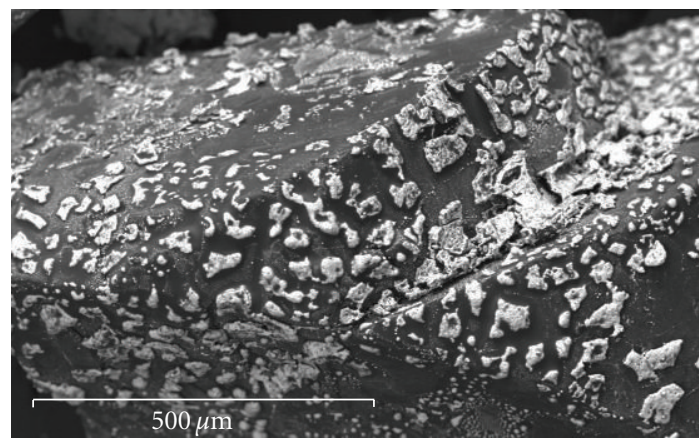

(b)

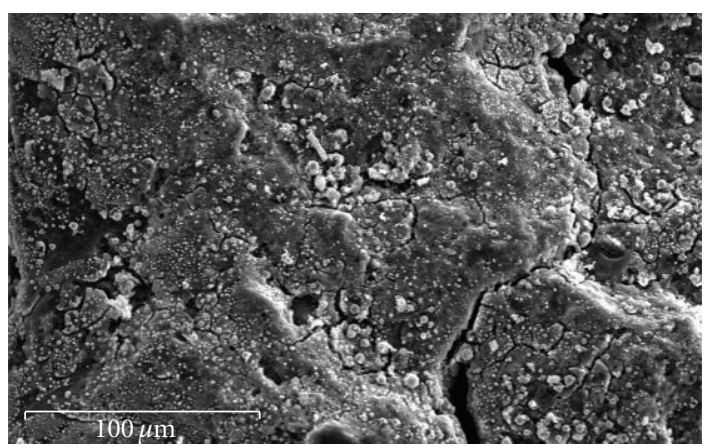

(d)

Figure 3: SEM images of iron coated (a) MN-1, (b) MN-2, (c) MN-3, and (d) MN-4. 


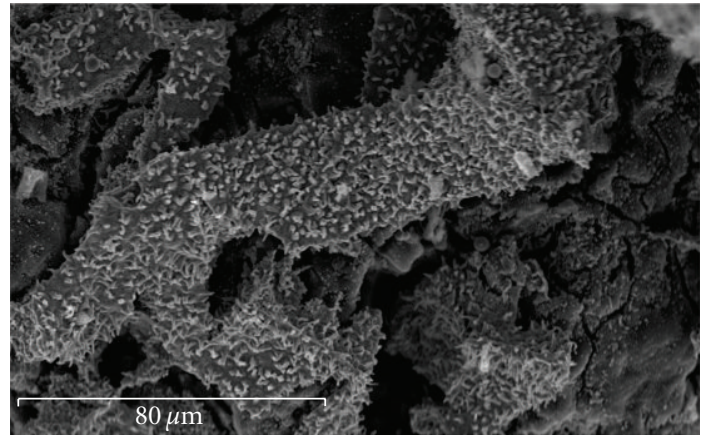

(a)

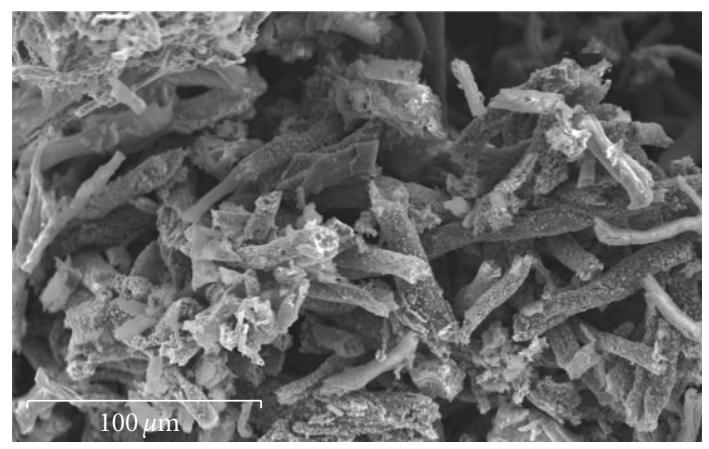

(c)

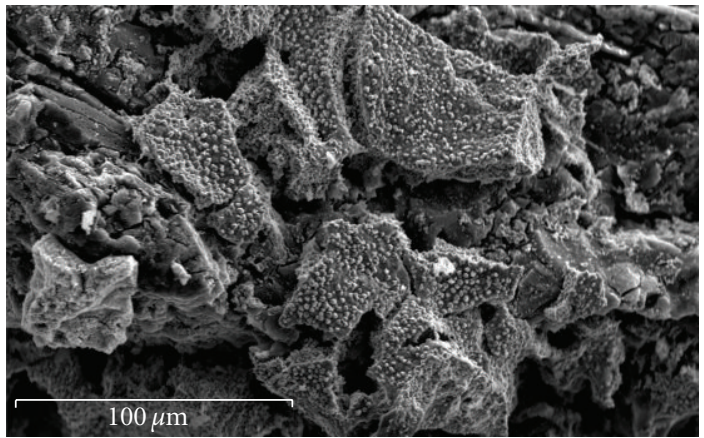

(b)

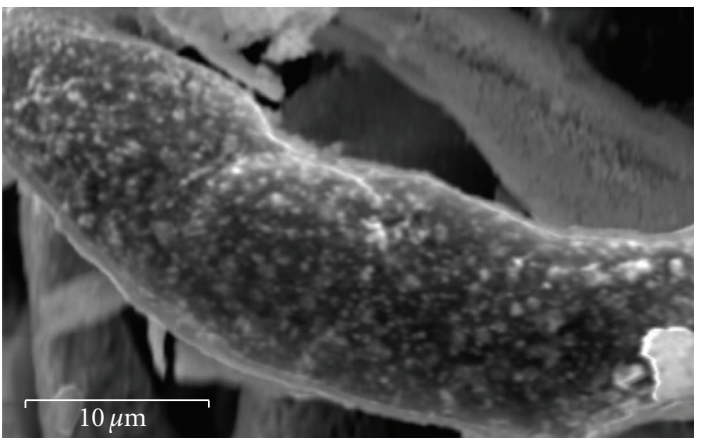

(d)

FIGURE 4: SEM Images of iron coated (a) MN-5, (b) MN-6, and (c-d) MN-7.

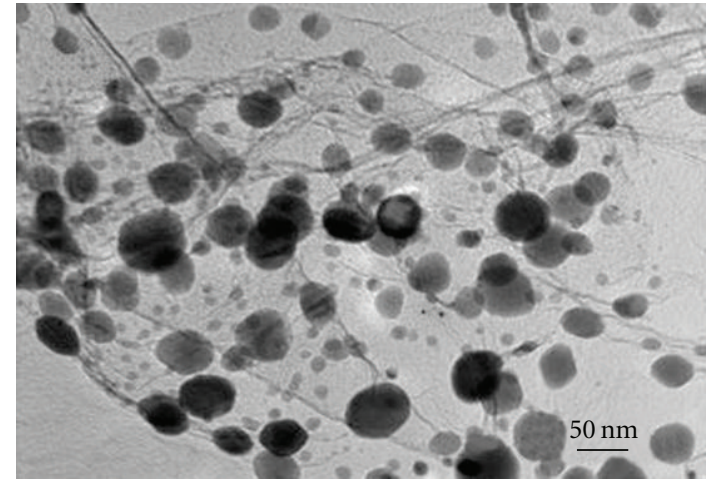

(a)

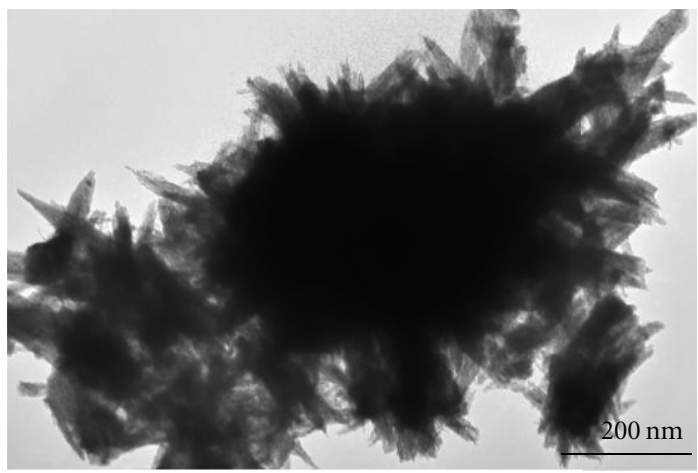

(c)

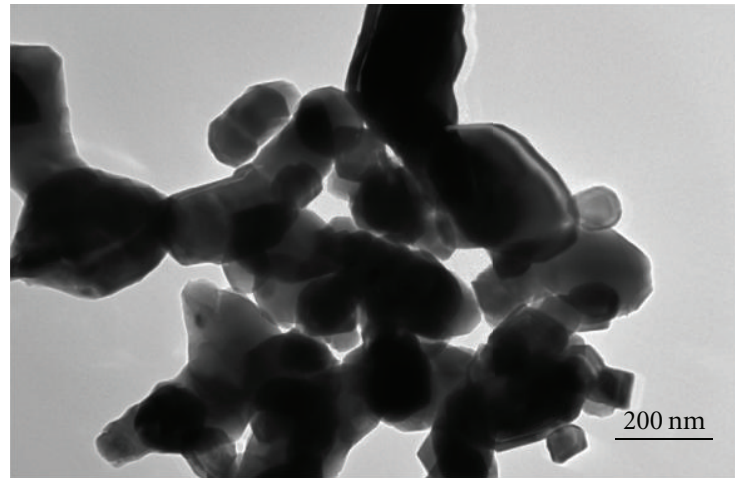

(b)

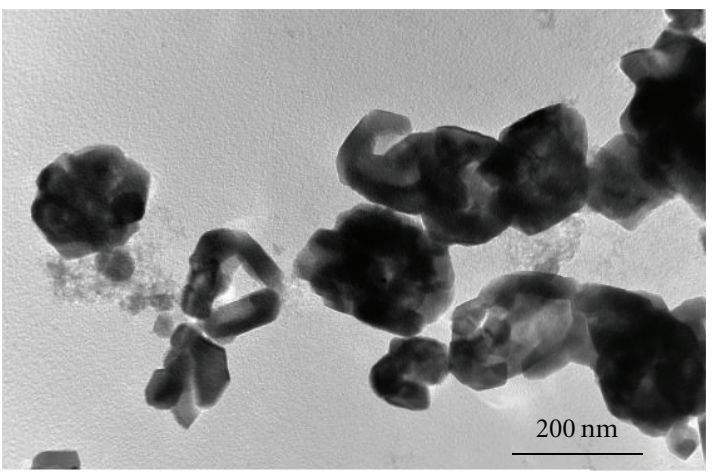

(d)

Figure 5: TEM images of iron coated (a) MN-1, (b) MN-2, (c) MN-3, and (d) MN-4. 


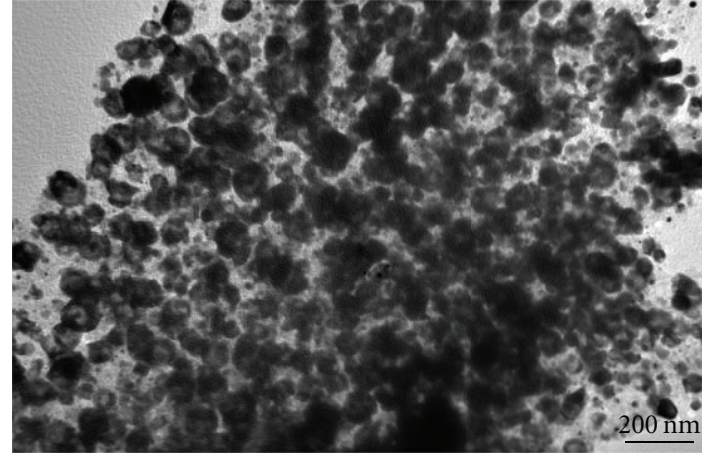

(a)

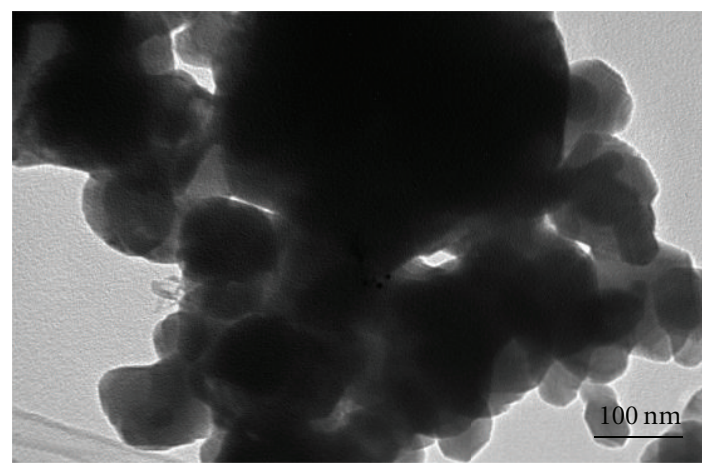

(c)

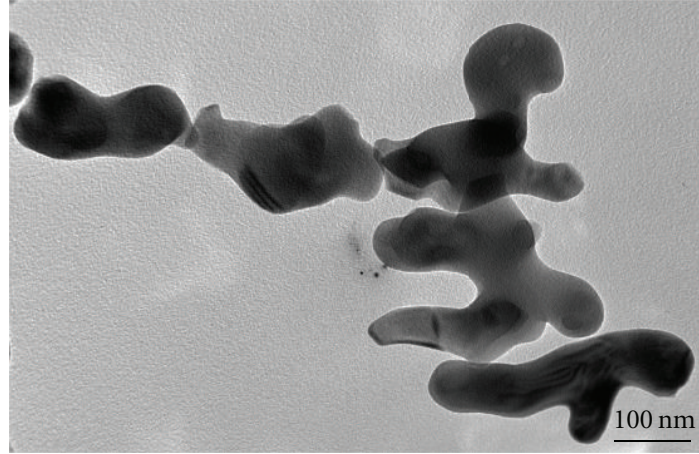

(b)

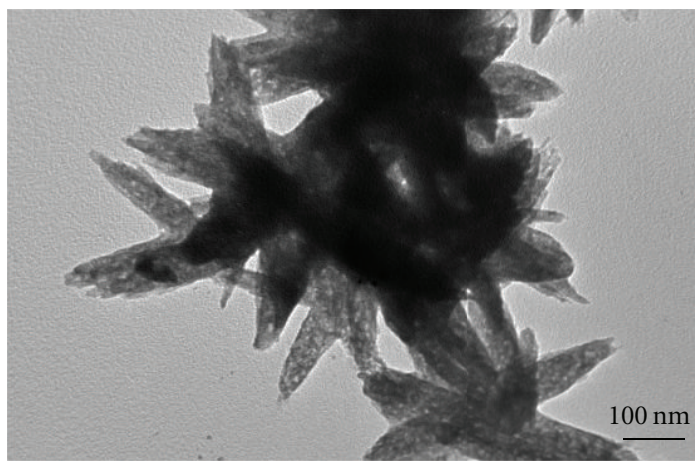

(d)

Figure 6: TEM images of iron coated (a) MN-5, (b) MN-6, (c) MN-7, and (d) MN-8 samples.

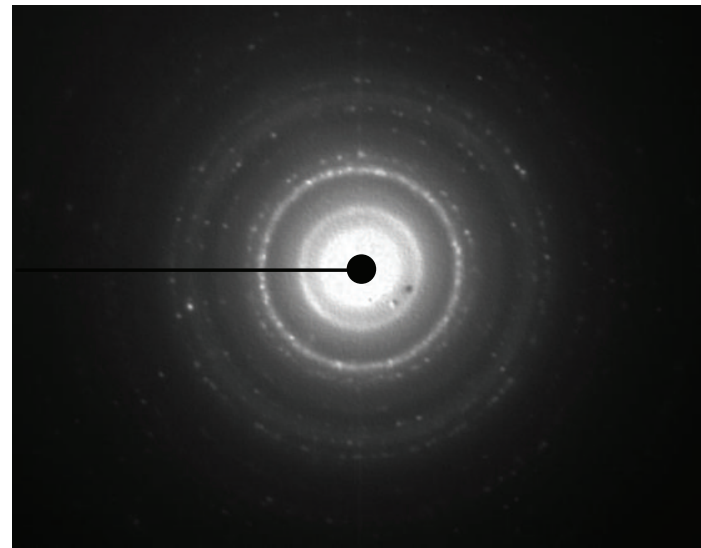

(a)

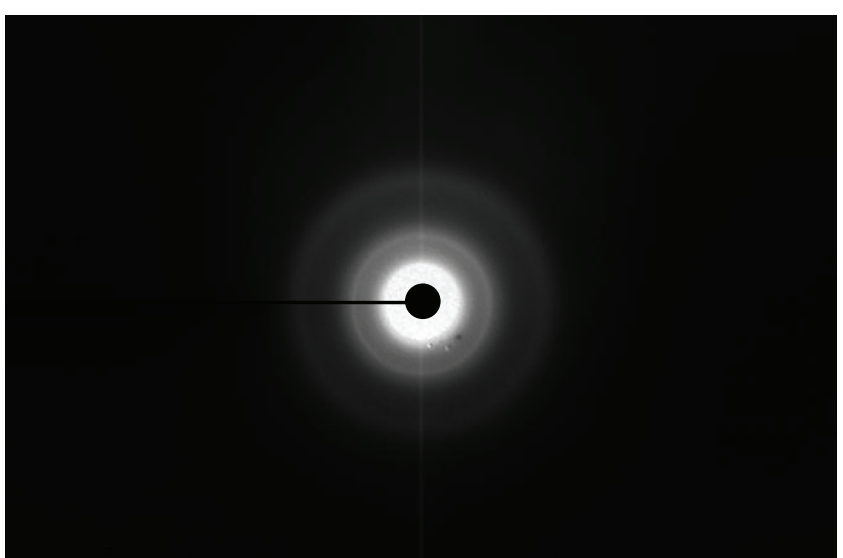

(b)

Figure 7: Selected area diffraction pattern (SAED) of (a) MN-1, and (b) MN-5 samples.

were added. Sample bottles were agitated by continuous tumbling for 48 hours. Approximately $60 \mathrm{~mL}$ of supernatant was extracted, filtered by $0.20 \mu \mathrm{m}$ syringe filter, and analyzed by inductively coupled plasma (ICP), and results are given in Figure 11 and Table 2.

A JEOL-1200EXII TEM with a side-mounted Gatan digital camera was used for the imaging of activated carbon, anthracite, cellulose fiber, and silica coated iron oxide/iron nanoparticles. Fifteen $\mu \mathrm{L}$ of iron oxide/iron nanoparticle coated activated carbon, anthracite, cellulose fiber, and silica samples were dispersed in acetone, placed on a formvarcarbon coated copper grid, and allowed to air dry. Images were captured at an accelerating voltage of $120 \mathrm{kV}$ and collected using Gatan software. For SEM, a JEOL-6490LV with an Oxford X-Act EDS system was used for imaging and elemental analysis. Images and EDS spectra were captured using an accelerating voltage of 15 to $30 \mathrm{kV}$. Spectra were collected for 50 live seconds using a process time of 5 percent, and a 30 to 50 percent dead-time. A Panalytical (Expert) 2-theta diffractometer with a copper $\mathrm{K} \alpha$ source was 


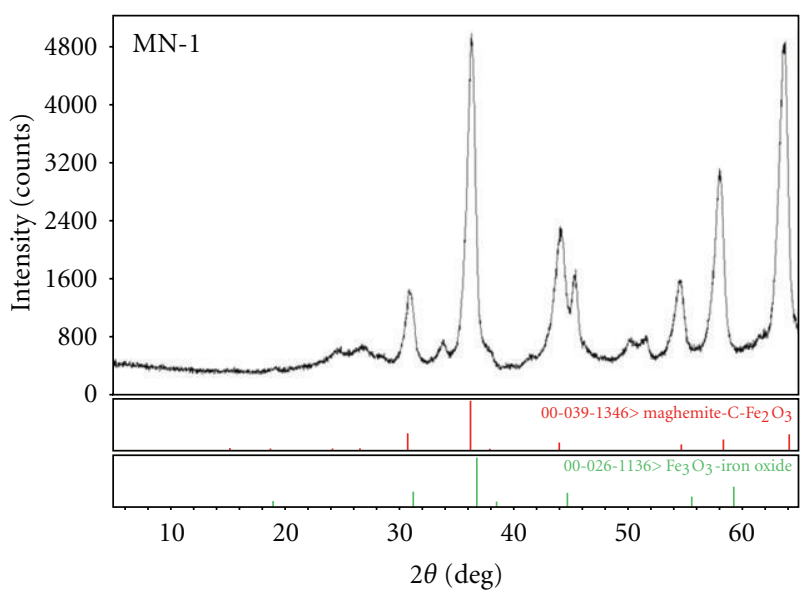

FIGURE 8: XRD pattern of maghemite coated anthracite synthesized using combustion reaction (MN-1 sample).

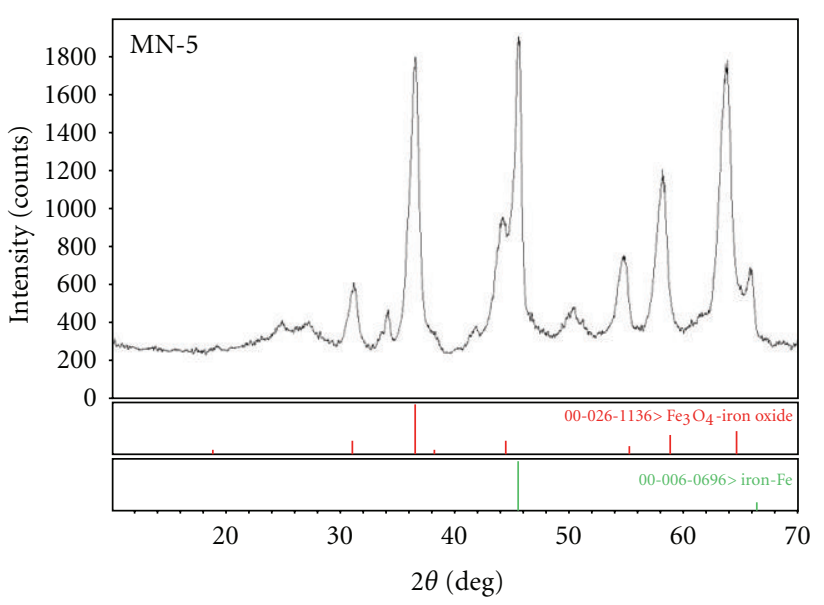

FIGURE 9: XRD pattern of maghemite coated commercial carbon synthesized using combustion reaction (MN-5 sample).

used to identify crystalline phases of the iron oxide/iron nanoparticle-coated activated carbon, anthracite, cellulose fiber, and silica samples. Scans were performed over a 2-theta ranging from 5 to $70^{\circ}$

\section{Results and Discussion}

Combustion synthesis or self-propagating high-temperature synthesis (SHS) provides striking realistic alternative to the conventional methods of producing advanced materials, such as ceramics, composites, and intermetallic compounds. The combustion procedure involves the decomposition of a reduction/ oxidation reaction system, which then proceeds as a self-sustaining front throughout the reactant gel mixture. The reaction conditions and the large amount of heat evolved during the reaction make possible the direct fabrication of a large number of single or multicomponent powders that are crystalline and homogeneous and have a narrow particle size distribution.

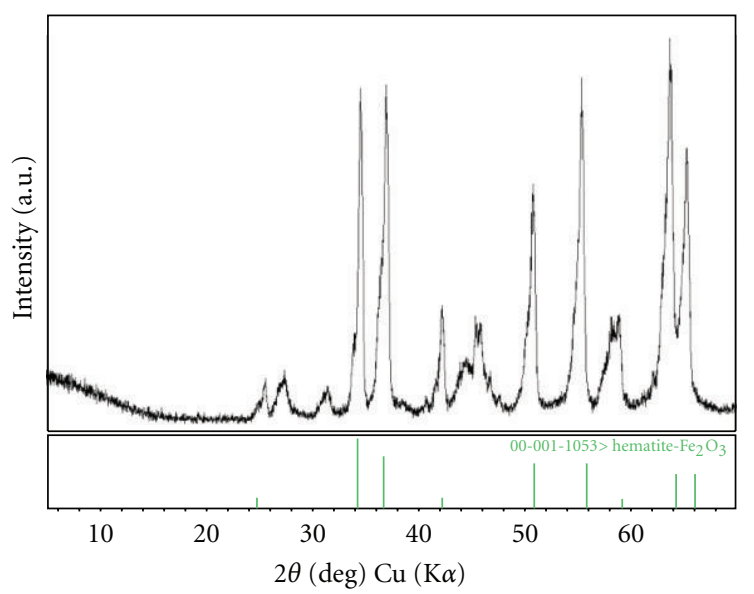

FIGURE 10: XRD pattern of hematite coated cellulose fibers synthesized using combustion reaction (MN-7 sample).

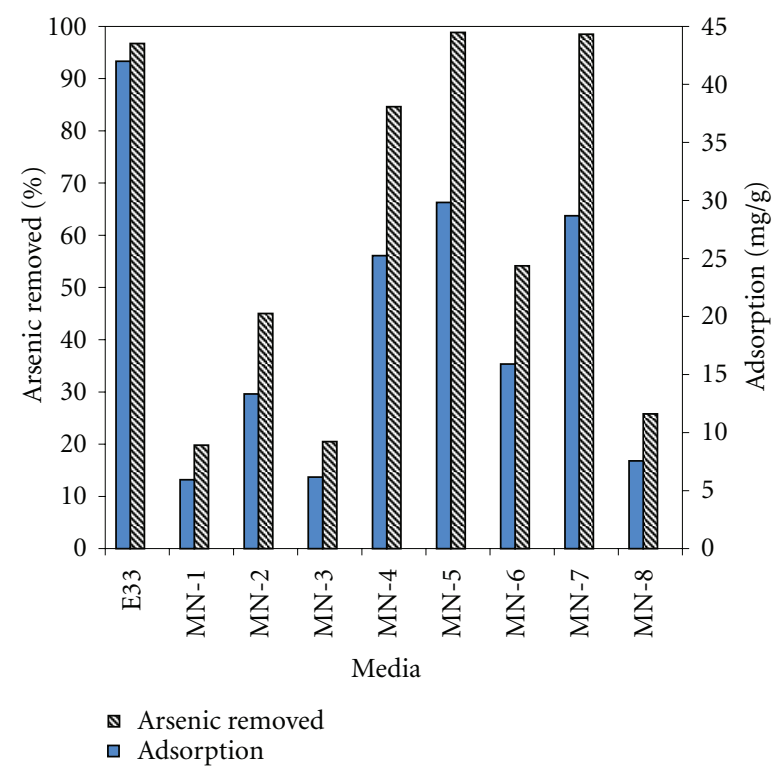

Figure 11: Arsenic adsorption study results.

The combustion synthesis of iron oxide/iron coated activated carbon, anthracite, cellulose fiber and silica samples were carried out in a kitchen microwave oven. The reaction uses activated carbon, anthracite, cellulose fiber and silica obtained from different vendors, and iron nitrate as precursor material for iron oxide/iron nanoparticlecoating. Nitrate, which was present in the precursor, $\mathrm{Fe}$ $\left(\mathrm{NO}_{3}\right)_{3} \cdot 9 \mathrm{H}_{2} \mathrm{O}$, can be used as a fuel for obtaining the desired materials. The different concentrations of iron nitrate with activated carbon, anthracite, cellulose fiber and silica were ignited using the microwave oven, in highly exothermic reactions completed within one to three minutes. A uniform coating of iron oxide/iron nanoparticles was observed (see Figures $1(\mathrm{a})-1(\mathrm{~d})$ and Figures $2(\mathrm{a})-2(\mathrm{c}))$. X-ray mapping images of $\mathrm{MN}-1$ (red-Fe, green-C, and blue-O), MN-2 (blue$\mathrm{Fe}$, green-O, and red-C), MN-3 (green-Fe, red-O, and blue$\mathrm{C}$ ), and MN-4 (red-Silica, green-Fe and blue-O) samples 
TABLE 1: Code, composition, and time of exposure of the reaction mixture.

\begin{tabular}{|c|c|c|c|}
\hline Sample number & Sample code & Sample composition & $\begin{array}{c}\text { Time exposed to } \\
\text { microwave } \\
\text { irradiation } \\
\text { (Min) }\end{array}$ \\
\hline 1 & NM1 & $\begin{array}{l}5.4 \mathrm{gm} \text { activated carbon }+8.8 \mathrm{gm} \text { of } \mathrm{Fe} \\
\left(\mathrm{NO}_{3}\right)_{3} \cdot 9 \mathrm{H}_{2} \mathrm{O}\end{array}$ & $1+1.5+3$ \\
\hline 2 & NM2 & $\begin{array}{l}9.9 \mathrm{gm} \text { anthracite }+4.9 \mathrm{gm} \text { of Fe } \\
\left(\mathrm{NO}_{3}\right)_{3} \cdot 9 \mathrm{H}_{2} \mathrm{O}+0.5 \mathrm{~mL} \mathrm{H} \mathrm{H}_{2} \mathrm{O}\end{array}$ & 2 \\
\hline 3 & NM3 & $\begin{array}{l}9.9 \mathrm{gm} \text { anthracite }+11.12 \mathrm{gm} \text { of } \mathrm{Fe} \\
\left(\mathrm{NO}_{3}\right)_{3} \cdot 9 \mathrm{H}_{2} \mathrm{O}+0.5 \mathrm{~mL} \mathrm{H} \mathrm{O}\end{array}$ & 2 \\
\hline 4 & NM4 & $\begin{array}{l}5 \text { gm carbon (Hydrodarco } 4000 \text {, lot No. } \\
873812)+11 \text { gm of Fe }\left(\mathrm{NO}_{3}\right)_{3} \cdot 9 \mathrm{H}_{2} \mathrm{O}+ \\
0.5 \mathrm{ml} \mathrm{H}_{2} \mathrm{O}\end{array}$ & 2 \\
\hline 5 & NM5 & $\begin{array}{l}5 \mathrm{gm} \text { carbon (Norit, GAC } 1240 \text { lot. } \\
30212-6)+11.2 \text { gm of Fe }\left(\mathrm{NO}_{3}\right)_{3} \cdot 9 \mathrm{H}_{2} \mathrm{O} \\
+0.5 \mathrm{~mL} \mathrm{H} \mathrm{O}\end{array}$ & 2 \\
\hline 6 & NM6 & $\begin{array}{l}5 \mathrm{gm} \text { activated carbon }+11.1 \mathrm{gm} \text { of Fe } \\
\left(\mathrm{NO}_{3}\right)_{3} \cdot 9 \mathrm{H}_{2} \mathrm{O}+0.5 \mathrm{~mL} \mathrm{H} \mathrm{H}_{2} \mathrm{O}\end{array}$ & 2 \\
\hline 7 & NM7 & $\begin{array}{l}4.92 \mathrm{gm} \text { cellulose fibrous long (sigma } \\
\text { batch.047k0142) }+11.98 \mathrm{Fe} \\
\left(\mathrm{NO}_{3}\right)_{3} \cdot 9 \mathrm{H}_{2} \mathrm{O}+0.5 \mathrm{~mL} \mathrm{H} \mathrm{O}\end{array}$ & $1+1$ \\
\hline 8 & NM8 & $\begin{array}{l}24.8 \text { gm of sand coarse }+9.8 \mathrm{Fe} \\
\left(\mathrm{NO}_{3}\right)_{3} \cdot 9 \mathrm{H}_{2} \mathrm{O}+0.5 \mathrm{~mL} \mathrm{H} \mathrm{H}_{2} \mathrm{O}\end{array}$ & 2 \\
\hline
\end{tabular}

TABLe 2: Arsenic adsorption study results.

\begin{tabular}{lcc}
\hline Sample name & As removed $(\%)$ & Adsorption $(\mathrm{mg} / \mathrm{g})$ \\
\hline E33 & 96.7 & 42.0 \\
MN-1 & 19.8 & 5.9 \\
MN-2 & 45.0 & 13.3 \\
MN-3 & 20.5 & 6.2 \\
MN-4 & 84.6 & 25.3 \\
MN-5 & 98.8 & 29.8 \\
MN-6 & 54.1 & 15.9 \\
MN-7 & 98.5 & 28.7 \\
MN-8 & 25.8 & 7.6 \\
\hline
\end{tabular}

are shown in Figures 1(a)-1(d), respectively. X-ray mapping studies indicate that iron nanoparticles are coated uniformly on the surface of carbon, anthracite, and silica. Similar coatings were observed for the MN-5 (red-Fe, green-C, and blue-oxygen), MN-6 (blue-Fe, green-O, and red-C), and $\mathrm{MN}-7$ (green-Fe, red-O, and blue-C) samples. The energy dispersive spectrum (EDS) indicates the presence of iron in each case, and a representative EDS image of MN-7 is shown in Figure 2(d).

In order to understand the surface morphology, crystal shape and size, SEM analysis performed on MN-1 to MN8 samples, and the results are shown in Figures 3 and 4 . Figure 3 shows the SEM images of the iron-coated MN1, MN-2, MN-3, and MN-4 samples. The iron oxide/iron nanoparticle coating varies from particles to flake depending upon the material used for preparation (see Figure 3). MN-1, MN-3, and MN-4 samples exhibit a spherical iron oxide/iron nanoparticle coating whereas $\mathrm{MN}-2$ displays a flake-like coating. The flake-like iron oxide/iron structures may result from insufficient fuel energy to break the iron into particles. Highly dispersed iron oxide/iron coatings appear on $\mathrm{MN}$ 5, MN-6, and MN-7 samples as shown in Figure 4. Notably, the MN-7 sample carbon, which was obtained from cellulose fiber, retained its parent structure even after modification with iron oxide/iron coating.

These fiber-based, carbon-coated iron oxide/iron materials exhibit numerous practical applications, including serving as membranes for arsenic removal. TEM studies confirm that nanoscale iron oxide/iron particles are achieved regardless of the material used for preparation (see Figures 5 and 6). $\mathrm{MN}-1$ and $\mathrm{MN}-2$ samples yielded spherical particles, while MN-3 yielded brush-like structures and MN-4 yielded ring-like structures (see Figure 5).

In the case of MN-5, MN-6, and MN-7, spherical-shaped structures were formed, while brush-like structures were formed on the MN-8 sample. For the selected samples, SAED results are shown in Figure 7. The samples crystallize in cubic symmetry. XRD was performed on all the synthesized samples and representative data are shown in Figures 810 (also see Figure S1-S5). Depending on the substrate and concentration of $\mathrm{Fe}\left(\mathrm{NO}_{3}\right)_{3}$ used, four major phase were identified, namely, maghemite $\left(\gamma-\mathrm{Fe}_{2} \mathrm{O}_{3}\right), \mathrm{Fe}_{3} \mathrm{O}_{4}$, hematite $\left(\alpha-\mathrm{Fe}_{2} \mathrm{O}_{3}\right)$, and $\mathrm{Fe}$ metal. Generally, broad XRD peaks indicate the coated iron particles of nanometer size.

Commercially available Bayoxide E33 (Bayer) is compared to these synthesized media for arsenic adsorption studies, and the data is shown in Figure 11 and Table 2. $\mathrm{MN}-4, \mathrm{MN}-5$, and $\mathrm{MN}-7$ show comparable arsenic removal capabilities at tested time interval. 


\section{Conclusions}

Combustion synthesis of iron oxide/iron nanoparticlecoated carbons such as activated carbon, anthracite, and silica is described. The reactions were carried out in alumina crucibles using a kitchen microwave oven, and the reaction completes within a few minutes. The method uses no additional fuel and uses a nitrate which is present in the precursor itself to drive the reaction. Depending upon the source of carbon used for the preparation, the formation of iron oxide/iron is observed. The coated iron oxide/iron nanoparticles were mostly spherical in nature, with size ranging from 50 to $400 \mathrm{~nm}$. In a few cases, however, such as MN-3 and MN-8, brush-like structures were observed. Samples MN-4, MN-5, and MN-7 had significant arsenic adsorption when compared with samples $\mathrm{MN}-1, \mathrm{MN}-2$, MN-3, MN-6, MN-8, and the E-33 control sample. The synthesized iron oxide/iron nanoparticle-coated activated carbon, anthracite, cellulose fiber, and silica samples may serve as a part of practical applications for environmental remediation, catalysis, membrane design, and other technological solutions.

\section{Disclaimer}

The U.S. Environmental Protection Agency, through its Office of Research and Development, funded and managed, or partially funded and collaborated in, the research described herein. It has been subjected to the Agency's peer and administrative review and has been approved for external publication. Any opinions expressed are those of the author(s) and do not necessarily reflect the views of the Agency, therefore, no official endorsement should be inferred. Any mention of trade names or commercial products does not constitute endorsement or recommendation for use.

\section{Acknowledgment}

The authors thank Christina Bennet-Stamper for the SEM images and Carlo Cruz for arsenic adsorption studies.

\section{References}

[1] G. S. Zhang, J. H. Qu, H. J. Liu, R. P. Liu, and G. T. Li, "Removal mechanism of As(III) by a novel Fe-Mn binary oxide adsorbent: oxidation and sorption," Environmental Science and Technology, vol. 41, no. 13, pp. 4613-4619, 2007.

[2] Y. Zhang, M. Yang, X. M. Dou, H. He, and D. S. Wang, "Arsenate adsorption on an Fe-Ce bimetal oxide adsorbent: role of surface properties," Environmental Science and Technology, vol. 39, no. 18, pp. 7246-7253, 2005.

[3] A. Violante, S. D. Gaudio, M. Pigna, M. Ricciardella, and D. Banerjee, "Coprecipitation of arsenate with metal oxides. 2. Nature, mineralogy, and reactivity of iron(III) precipitates," Environmental Science and Technology, vol. 41, no. 24, pp. 8275-8280, 2007.

[4] J. Zhang and R. Stanforth, "Slow adsorption reaction between arsenic species and goethite $(\alpha-\mathrm{FeOOH})$ : diffusion or heterogeneous surface reaction control," Langmuir, vol. 21, no. 7, pp. 2895-2901, 2005.
[5] A. B. M. Giasuddin, S. R. Kanel, and H. Choi, "Adsorption of humic acid onto nanoscale zerovalent iron and its effect on arsenic removal," Environmental Science and Technology, vol. 41, no. 6, pp. 2022-2027, 2007.

[6] S. R. Kanel, B. Manning, L. Charlet, and H. Choi, "Removal of arsenic(III) from groundwater by nanoscale zero-valent iron," Environmental Science and Technology, vol. 39, no. 5, pp. 12911298, 2005.

[7] Y. Jia, L. Xu, Z. Fang, and G. P. Demopoulos, "Observation of surface precipitation of arsenate on ferrihydrite," Environmental Science and Technology, vol. 40, no. 10, pp. 3248-3253, 2006.

[8] Y. Jia and G. P. Demopoulos, "Adsorption of arsenate onto ferrihydrite from aqueous solution: influence of media (sulfate vs nitrate), added gypsum, and $\mathrm{pH}$ alteration," Environmental Science and Technology, vol. 39, no. 24, pp. 9523-9527, 2005.

[9] X. Guo and F. Chen, "Removal of arsenic by bead cellulose loaded with iron oxyhydroxide from groundwater," Environmental Science and Technology, vol. 39, no. 17, pp. 6808-6818, 2005.

[10] B. J. Lafferty and R. H. Loeppert, "Methyl arsenic adsorption and desorption behavior on iron oxides," Environmental Science and Technology, vol. 39, no. 7, pp. 2120-2127, 2005.

[11] M. Jang, S. H. Min, T. H. Kim, and J. K. Park, "Removal of arsenite and arsenate using hydrous ferric oxide incorporated into naturally occurring porous diatomite," Environmental Science and Technology, vol. 40, no. 5, pp. 1636-1643, 2006.

[12] D. Mishra and J. Farrell, "Evaluation of mixed valent iron oxides as reactive adsorbents for arsenic removal," Environmental Science and Technology, vol. 39, no. 24, pp. 9689-9694, 2005.

[13] K. J. Bisceglia, K. J. Rader, R. F. Carbonaro, K. J. Farley, J. D. Mahony, and D. M. Di Toro, "Iron(II)-catalyzed oxidation of arsenic(III) in a sediment column," Environmental Science and Technology, vol. 39, no. 23, pp. 9217-9222, 2005.

[14] Z. Gu, J. Fang, and B. Deng, "Preparation and evaluation of GAC-based iron-containing adsorbents for arsenic removal," Environmental Science and Technology, vol. 39, no. 10, pp. 3833-3843, 2005. 

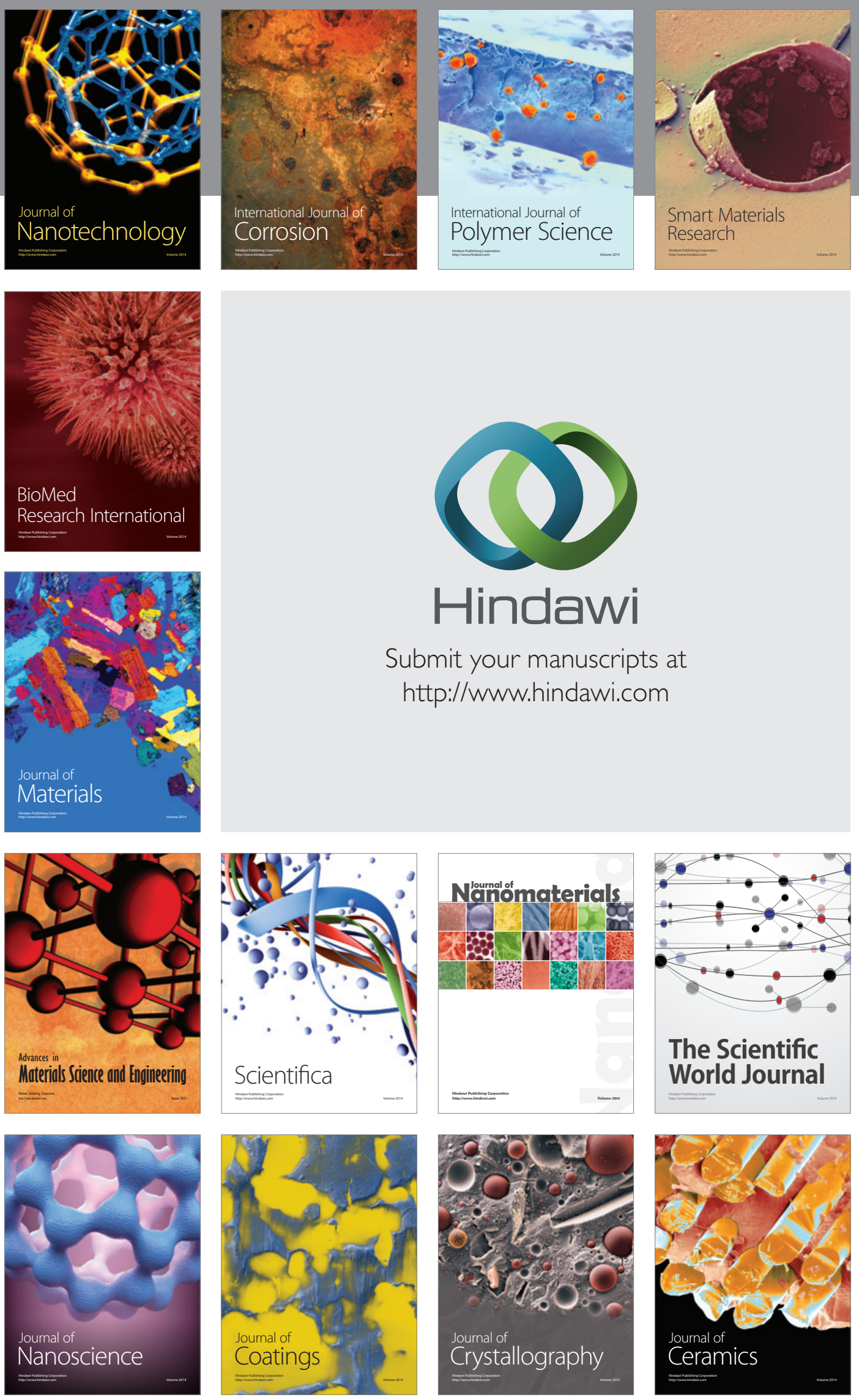

The Scientific World Journal

Submit your manuscripts at

http://www.hindawi.com

\section{World Journal}

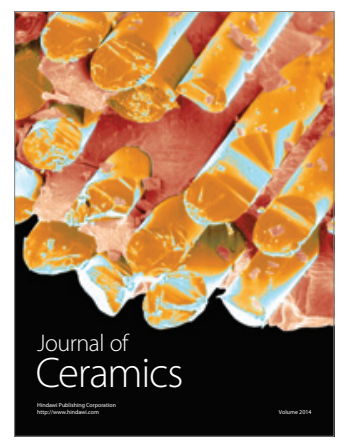

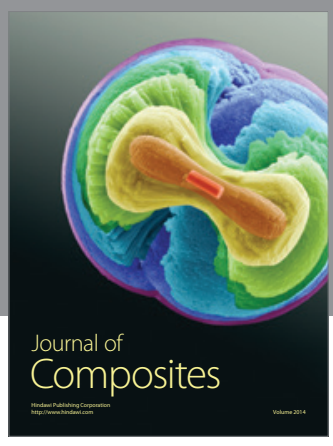
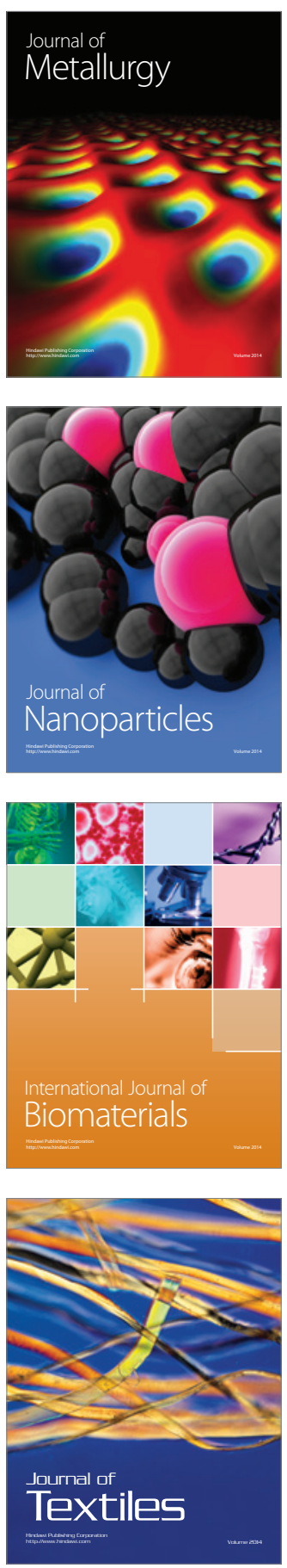